\title{
Delayed Use of the Recombinant Human IL-1 Receptor Antagonist Anakinra in Five COVID-19 Patients with Pulmonary Fibrosis and Persistent Hypoxaemia: A Preliminary Report
}

\author{
Daniel Nan ${ }^{1,2}$, Cristina Abraira-Meriel3, Sandra de la Roz-Fernández ${ }^{1}$, Tamara Maestre-Orozco ${ }^{1}$, \\ Jose Luis Hernandez ${ }^{1,2}$, Marta Fernandez-Ayala ${ }^{1}$ \\ ${ }^{1}$ Internal Medicine Department, University Hospital Marqués de Valdecilla, Santander, Spain \\ ${ }^{2}$ University of Cantabria, Santander, Spain \\ ${ }^{3}$ Dermatology Department, University Hospital Marqués de Valdecilla, Santander, Spain
}

Doi: 10.12890/2021_002821 - European Journal of Case Reports in Internal Medicine - ๑ EFIM 2021

Received: 07/08/2021

Accepted: $26 / 08 / 2021$

Published: 08/10/2021

\begin{abstract}
How to cite this article: Nan D, Abraira-Merlier C, de la Roz-Fernández S, Maestre-Orozco T, Hernandez JL, Fernandez-Ayala M. Delayed use of the recombinant human IL-1 receptor antagonist anakinra in five COVID-19 patients with pulmonary fibrosis and persistent hypoxaemia: a preliminary report. EJCRIM 2021;8: doi:10.12890/2021_002821.
\end{abstract}

Conflicts of Interests: The authors declare there are no competing interests.

This article is licensed under a Commons Attribution Non-Commercial 4.0 License

\section{ABSTRACT}

Coronavirus disease 2019 (COVID-19) is currently a major public health problem. The development of pulmonary fibrosis secondary to acute respiratory distress syndrome (ARDS) is one of the expected sequelae. In this case series, we describe five instances of the use of anakinra in late-phase COVID-19 pneumonia in hospitalized patients with pulmonary fibrosis and refractory respiratory failure fulfilling ARDS criteria. The study demonstrates that anakinra has promising efficacy and safety in late-phase COVID-19 infection in patients with ARDS and refractory hypoxaemia, and suggests its potential application as antifibrotic therapy in these patients.

\section{LEARNING POINTS}

- Up to one third of patients with severe COVID-19 pneumonia progress to acute respiratory distress syndrome (ARDS).

- Pulmonary fibrosis is a known consequence of ARDS.

- Our study shows promising results regarding the efficacy and safety of anakinra used in late-phase COVID-19 infection in patients with pulmonary fibrosis secondary to ARDS.

\section{KEYWORDS}

Pulmonary fibrosis, COVID-19, anakinra

\section{INTRODUCTION}

Up to one third of patients with severe COVID-19 pneumonia progress to acute respiratory distress syndrome (ARDS) ${ }^{[1]}$. The prevalence of post-COVID-19 fibrosis is still unknown, although recent studies have shown that $47 \%$ of patients have reduced oxygen diffusion and $25 \%$ reduced total lung capacity at discharge, these effects being more frequent in those with severe disease ${ }^{[2]}$.

Regarding the proinflammatory pathways involved in the development of fibrosis, it seems that SARS-CoV-2 employs different molecular pathways to activate the NLPR3 inflammasome related to interleukin (IL)-1 and IL-6 secretion to trigger the cytokine cascade that causes severe lung damage ${ }^{[3]}$. 
Anakinra is a recombinant human IL-1 receptor antagonist with a short half-life (3-4 h) that neutralizes the biological activity of IL-1 $\alpha$ and IL-1 $\beta$ by competitively inhibiting their binding to the receptor. Most studies have evaluated the use of anakinra in the early stages of SARSCoV-2 infection, with substantial differences in their design and results ${ }^{[4]}$.

We report a case and review a case series describing the use of anakinra in late-phase COVID-19 pneumonia in hospitalized patients with refractory respiratory failure and pulmonary fibrosis.

\section{CASE REPORT}

Patient 1 was a 65-year-old non-smoking woman with a history of arterial hypertension, hepatic steatosis, osteoporosis and surgical intervention for left parotid adenoma. She was admitted on $26 \mathrm{March} 2020$ due to a 10 -day clinical course of fever above $38^{\circ} \mathrm{C}$ and diarrhoea in the previous 24 hours, presenting bilateral pulmonary infiltrates on chest x-ray compatible with COVID-19 pneumonia with moderate parenchymal involvement, hypoxaemia with $\mathrm{PaO}_{2} / \mathrm{FiO}_{2} 319 \mathrm{mmHg}$ and a positive RT-PCR assay on oropharyngeal swab for SARS-CoV-2. On admission, specific treatment with azithromycin, hydroxychloroquine and lopinavir/ritonavir was started. The patient also received low-molecular-weight heparin and low-flow oxygen therapy with a nasal canula. After 6 days (16 following disease onset), she presented radiological and clinical worsening with $\mathrm{PaO}_{2} / \mathrm{FiO}_{2}$ of $230 \mathrm{mmHg}$ and it was decided to add corticosteroids (cumulate dose of 440 mg of methylprednisolone) and in the following 24 hours, a single dose of tocilizumab $600 \mathrm{mg}$ (IL-6 $142 \mathrm{pg} / \mathrm{ml}$ ). In the subsequent clinical evolution, dyspnoea persisted on minimal effort as well as hypoxaemia $\left(\mathrm{PaO}_{2} / \mathrm{FiO}_{2} 252 \mathrm{mmHg}\right)$ and ferritin increased to $1115 \mu \mathrm{g} / \mathrm{l}$ and $\mathrm{D}$-dimer to $1999 \mathrm{ng} / \mathrm{ml}$. Consequently, on day 15 of admission (day 25 of disease), a lung CT scan was performed and showed ground-glass opacities and fibrosis mainly after diffuse alveolar damage. In view of these findings, it was decided to prescribe anakinra, at a dose of $200 \mathrm{mg}$ twice daily for the first day (two doses), and then $100 \mathrm{mg}$ daily for the following 2 days (cumulative dose $600 \mathrm{mg}$ ).

The clinical evolution was satisfactory with correction of hypoxaemia $\left(\mathrm{PaO}_{2} / \mathrm{FiO}_{2} 314 \mathrm{mmHg}\right.$ ) and inflammatory parameters (ferritin 500 $\mu \mathrm{g} / \mathrm{l}, \mathrm{D}$-dimers $650 \mathrm{ng} / \mathrm{ml}$ ). The patient was discharged 2 days after the last dose of anakinra with no need for oxygen therapy and $\mathrm{PaO}_{2} / \mathrm{FiO}_{2}$ $413 \mathrm{mmHg}$. The patient was followed up twice as an outpatient in August and December 2020. She had no respiratory symptoms and a new control lung CT scan in December showed decreased pulmonary fibrosis.

\section{CASE SERIES}

In view of the satisfactory results for patient 1, a retrospective observational study of a case series was performed. The study was conducted in a 900-bed tertiary care hospital in Spain. All patients who received anakinra between 1 March 2020 and 1 January 2021 in the inpatient wards were identified through their pharmaceutical records. Subsequently, those who received anakinra at least 2 weeks after symptom onset were selected. Demographic data and relevant clinical characteristics such as comorbidities associated with increased severity of COVID-19 pneumonia, immunosuppressive treatment received and number of days after symptom onset, were collected from the electronic medical record. The number of days after symptom onset before anakinra was administered was registered, as well as the regimen and cumulative dose. As efficacy variables, we recorded the time of oxygen therapy support, $\mathrm{PaO} 2 / \mathrm{FiO} 2$, analytical variables and chest imaging available before and $48 \mathrm{~h}$ after the last dose administered. Abnormalities compatible with pulmonary fibrosis in those in whom CT was performed were also assessed. The time and $\mathrm{PaO}_{2} / \mathrm{FiO}_{2}$ at discharge were documented, as well as survival and availability of lung CT in the 8 months after administration. Adverse events within 7 days after anakinra administration were noted.

\section{RESULTS}

A total of 17 patients with COVID-19 received anakinra on inpatient wards; five of these, including our patient, received it at least 2 weeks after symptom onset (mean 23.6 days, range 19-29).

Table 1 summarizes the main characteristics of the patients. Four men and one woman with a mean age of 74.4 years (range 66-82) were included. All received a total cumulative dose of $600 \mathrm{mg}$ subcutaneous anakinra, with a loading dose of two doses of $200 \mathrm{mg}$ twice daily, followed by $100 \mathrm{mg}$ daily for 2 days; in one of the patients the maintenance dose was administered every 48 hours adjusted for his impaired renal function.

All patients had hypoxaemic refractory respiratory failure fulfilling ARDS criteria with a mean $\mathrm{PaO}_{2} / \mathrm{FiO}_{2}$ of $180.2 \mathrm{mmHg}$ (range $128-252$ ) and chest $x$-ray with bilateral infiltrates compatible with ARDS.

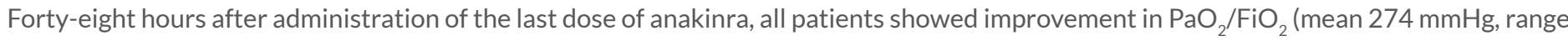
172-341) as well as at hospital discharge (mean 346.2 mmHg, range 291-413). Figure 1 shows the evolution of the patients' PaO2/FiO2 measurements.

All patients had chest $\mathrm{x}$-rays before and after anakinra administration, which showed regression of the infiltrates in three patients and radiographic stability in the remaining two 48 hours after the last dose. A CT scan was only performed in three patients and revealed interstitial abnormalities compatible with pulmonary fibrosis in all three (Fig. 2). 


\begin{tabular}{|c|c|c|c|c|c|}
\hline & P1 & P2 & P3 & P4 & P5 \\
\hline Age/sex & $66 / F$ & $81 / M$ & $75 / M$ & $68 / \mathrm{M}$ & $82 / \mathrm{M}$ \\
\hline $\begin{array}{l}\text { Risk factors for severe } \\
\text { COVID-19 }\end{array}$ & Hypertension & $\begin{array}{l}\text { Hypertension, } \\
\text { obesity }\end{array}$ & $\begin{array}{l}\text { Hypertension, } \\
\text { leukaemia }\end{array}$ & $\begin{array}{l}\text { Hypertension, } \\
\text { obesity }\end{array}$ & \\
\hline $\begin{array}{l}\text { Previous immunosup- } \\
\text { pressive therapy (days } \\
\text { after disease onset) }\end{array}$ & $\begin{array}{l}\text { Corticosteroids (15) } \\
\text { Tocilizumab (16) }\end{array}$ & Corticosteroids (7) & $\begin{array}{l}\text { Corticosteroids (16) } \\
\text { Tocilizumab (22) }\end{array}$ & $\begin{array}{l}\text { Corticosteroids (7) } \\
\text { Tocilizumab (7) }\end{array}$ & $\begin{array}{l}\text { Corticosteroids (17) } \\
\text { Tocilizumab (17) }\end{array}$ \\
\hline $\begin{array}{l}\text { Duration of COVID-19 } \\
\text { symptoms (days before } \\
\text { anakinra) }\end{array}$ & 25 & 29 & 25 & 19 & 20 \\
\hline $\begin{array}{l}\text { Days of oxygen therapy } \\
\text { support } \\
\text { before/aftert anakinra }\end{array}$ & $16 / 1$ & $26 / 3$ & $15 / 11$ & $14 / 4$ & $14 / 23^{*}$ \\
\hline $\begin{array}{l}\text { PAO2/FIO2 (mmhg) } \\
\text { before/aftert anakinra }\end{array}$ & $252 / 341$ & $163 / 256$ & $190 / 304$ & $168 / 297$ & $128 / 172$ \\
\hline $\begin{array}{l}\text { PAO2/FIO2 (MMHG) } \\
\text { at discharge }\end{array}$ & 413 & 291 & 343 & 390 & 294 \\
\hline $\begin{array}{l}\text { D-dimer (ng/ml) } \\
\text { before/aftert anakinra }\end{array}$ & $1999 / 650$ & $2268 / 830$ & $1149 / 815$ & $1197 / 1195$ & $3621 / 5023$ \\
\hline $\begin{array}{l}\text { Ferritin }(\mu \mathrm{g} / \mathrm{l}) \\
\text { before/aftert anakinra }\end{array}$ & $1115 / 500$ & $1175 / 918$ & $780 / 487$ & $1581 / 1695$ & $973 / 950$ \\
\hline $\begin{array}{l}\text { Lymphocytes } \times 103 / \mu l \\
\text { before/aftert anakinra }\end{array}$ & $0.9 / 1.6$ & $0.9 / 1.2$ & $5.9 / 6.1$ & $0.5 / 0.7$ & $0.5 / 0.7$ \\
\hline $\begin{array}{l}\text { Time to discharge after } \\
\text { anakinra (days) }\end{array}$ & 2 & 3 & 13 & 6 & 23 \\
\hline $\begin{array}{l}\text { Adverse events after } \\
\text { anakinra }\end{array}$ & - & - & - & Neutropenia & $\begin{array}{l}\text { Neutropenia } \\
\text { Increase } \times 3 \text { liver tran- } \\
\text { saminases }\end{array}$ \\
\hline $\begin{array}{l}\text { Thorax radiology after } \\
\text { anakinra }\end{array}$ & $\begin{array}{l}\text { Regression of infil- } \\
\text { trates }\end{array}$ & $\begin{array}{l}\text { Regression of infil- } \\
\text { trates }\end{array}$ & Stable infiltrates & $\begin{array}{l}\text { Regression of infil- } \\
\text { trates }\end{array}$ & Stable infiltrates \\
\hline CT after anakinra & Regression of fibrosis & Regression of fibrosis & Regression of fibrosis & NA & NA \\
\hline
\end{tabular}

Table 1. Characteristics and outcomes of the five patients

Cumulative dose of anakinra: $600 \mathrm{mg}$ (loading dose $200 \mathrm{mg} / 12 \mathrm{~h} \times 2$ doses followed with $100 \mathrm{mg} / 24 \mathrm{~h} \times 2$ doses or $48 \mathrm{~h}$ if renal impairment).

$\uparrow 48$ Hours after last dose of anakinra. ${ }^{*}$ Discharge with low flow oxygen therapy. Na, not applicable; $p$, patient. 
All patients were still alive at follow-up, four of them after 12 months and one after 3 months at the end of the study. The three patients with lung CT scan images available before the start of anakinra, and at 7, 2.5 and 6 months, respectively, showed complete resolution of fibrosis (Fig. 2).
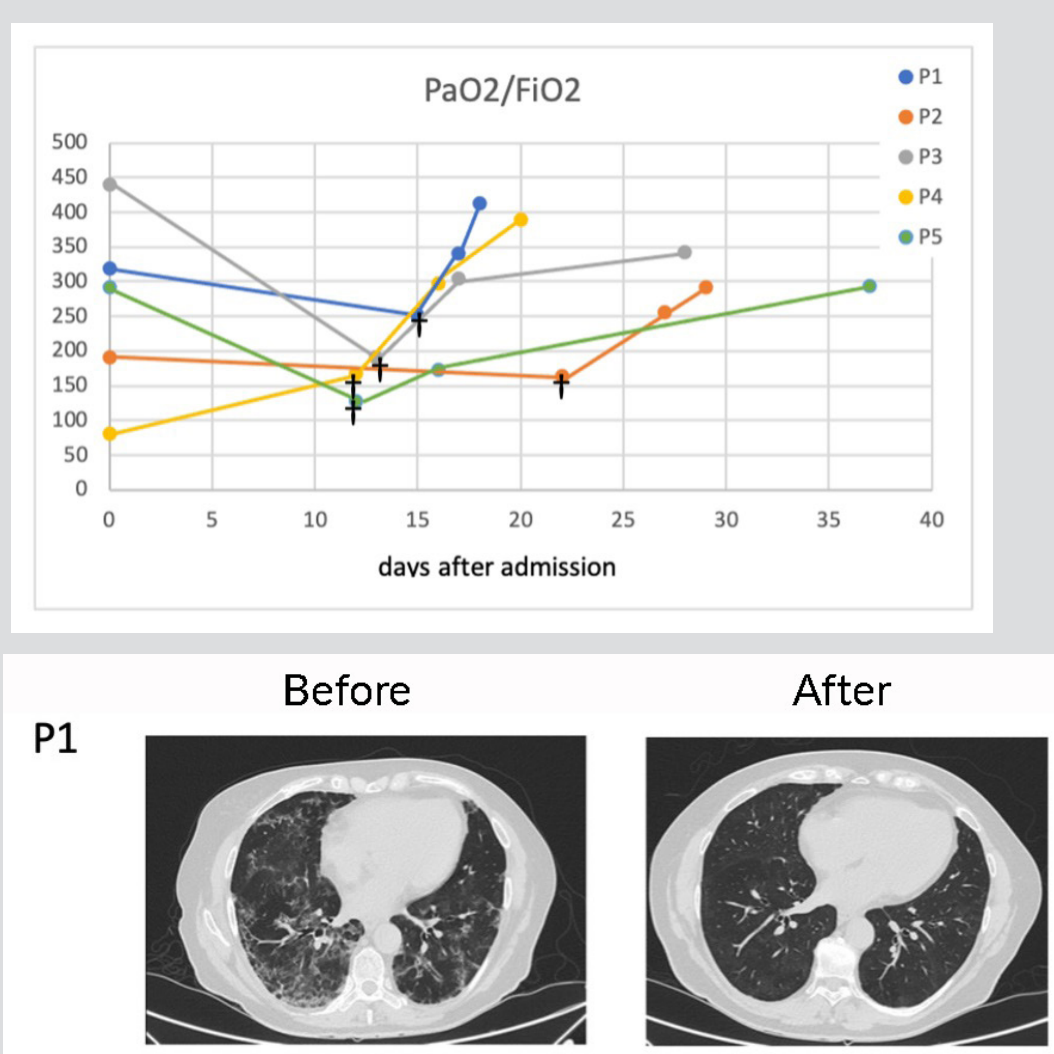

P2
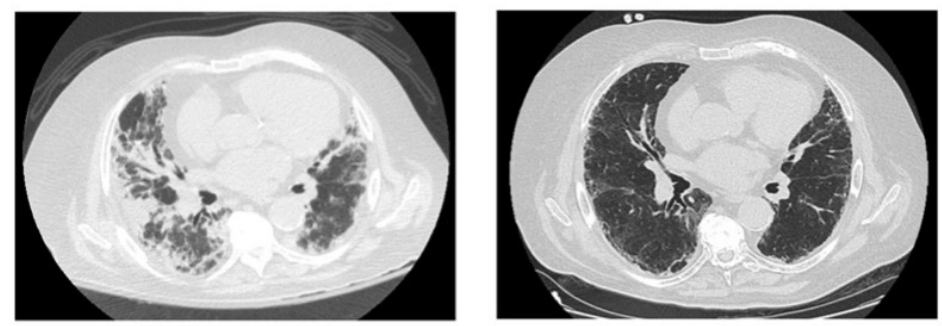

P3
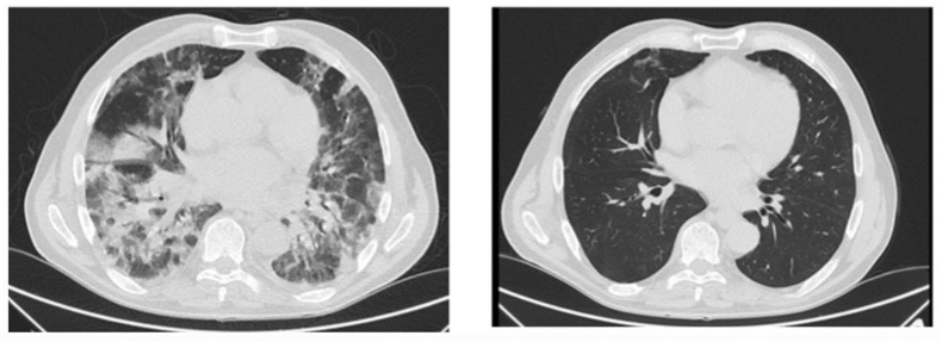

Figure 2. Lung $C T$ images of patients before and after anakinra. (P1, left column) 7 Months after anakinra; ( $P 2$, left column) 2.5 months after anakinra; (P3, left column) 6 months after anakinra. P, patient

\section{DISCUSSION}

To our knowledge, this is the first report evaluating the use of anakinra as a treatment for refractory hypoxaemia and fibrosis secondary to ARDS caused by COVID-19. 
All patients had a satisfactory response with improvement in respiratory and clinical parameters, allowing them to be discharged from hospital in the following days. During subsequent follow-up, evolution was favourable in all patients, with resolution of fibrosis in those patients who had lung CT scans.

No serious adverse effects or secondary infections were reported in our study, although this may have been influenced by the limited number of patients included.

The patients in our series had similar characteristics in terms of age and comorbidities to those described in published studies of patients with moderate-severe COVID-19 ${ }^{[5]}$. Also, previous treatment with corticosteroids and anti-IL6 (tocilizumab) is commonly administered in clinical practice in patients with similar severity ${ }^{[4,6]}$. The anakinra regimen, with a cumulative dose of 600 mg, is similar to those in most previous reports ${ }^{[7-9]}$, with the exception of the study by Cavalli et al., which used higher doses ( $5 \mathrm{mg} / \mathrm{kg}$ twice daily intravenously) and was one of the few to demonstrate a significant increase in survival ${ }^{[8]}$. In all studies, the drug was administered in the first 2 weeks after symptom onset (range 3-13 days). Only two of the studies demonstrated a significant reduction in mortality ${ }^{[8,9]}$, and the only randomized clinical trial available, CORINMUNO-19, with 116 patients, failed to demonstrate clinical improvement, although it should be noted that the patients included had a lower severity profile than in other studies and did not have to meet the clinical criteria for ARDS for inclusion [9].

Of note, in none of the available COVID-19 studies was anakinra used in the late phase of infection, and also the outcomes were not based on improvement in refractory hypoxaemia or pulmonary fibrosis, which are the two most important measures studied in our case series.

Our study has important limitations because of its retrospective and non-randomized design, so there may many confounding factors, as well as the small number of patients included. We should also highlight the fact that four of the five patients were previously treated with tocilizumab, although with a suboptimal initial response: due to the long half-life of this drug (between 6 and 18 days), we cannot rule out that the subsequent use of anakinra could have had a synergistic effect. In fact, several in vitro studies have shown that the combined effect of IL-6 and IL-1 is linked to SARS-CoV2-mediated severe lung damage ${ }^{[2,10]}$.

Although prospective studies on the long-term pulmonary consequences of COVID-19 infection are lacking, given the increasing number of patients affected, it is crucial to identify those at risk of fibrosis development in order to provide an appropriate clinical and therapeutic approach, including their enrolment in clinical trials ${ }^{[5]}$.

Experience in the use of immunosuppressive therapies in COVID-19-associated pulmonary fibrosis is rare, although there are several clinical trials in progress with different molecules, including nintedanib and pirfenidone, whose mechanisms of action also involve the inhibition of IL-1 and IL-6 ${ }^{[2,11,12]}$.

In summary, our study shows promising results regarding the efficacy and safety of anakinra used in late-phase COVID-19 infection, in patients with ARDS and refractory hypoxaemia, and shows it could potentially be applied as an antifibrotic therapy in these patients.

These preliminary results, given the limitations of the study design, provide new evidence regarding the management of post-COVID fibrosis which could contribute to future prospective and clinical trials.

\section{REFERENCES}

1. Zhou F, Yu T, Du R, Fan G, Liu Y, Liu Z, et al. Clinical course and risk factors for mortality of adult inpatients with COVID-19 in Wuhan, China: a retrospective cohort study Lancet 2020;395:1054-1062.

2. George PM, Wells AU, Jenkins RG. Pulmonary fibrosis and COVID-19: the potential role for antifibrotic therapy. Lancet Respir Med 2020;8(8):807-815.

3. Borthwick LA. The IL-1 cytokine family and its role in inflammation and fibrosis in the lung. Semin Immunopathol 2016;38(4):517-534.

4. Khan FA, Stewart I, Fabbri L, Moss S, Robinson K, Smyth AR, et al. Systematic review and meta-analysis of anakinra, sarilumab, siltuximab and tocilizumab for COVID-19. Thorax 2021;76(9):907-919.

5. Spagnolo P, Balestro E, Aliberti S, Cocconcelli E, Biondini D, Della Casa G, et al. Pulmonary fibrosis secondary to COVID-19: a call to arms? Lancet Respir Med 2020;8(8):750752.

6. RECOVERY Collaborative Group, Horby P, Lim WS, Emberson JR, Mafham M, Bell JL, et al. Dexamethasone in hospitalized patients with Covid-19. N Engl J Med 2021;384(8):693-704.

7. Aouba A, Baldolli A, Geffray L, Verdon R, Bergot E, Martin-Silva N, Justet A. Targeting the inflammatory cascade with anakinra in moderate to severe COVID-19 pneumonia: case series. Ann Rheum Dis 2020;79(10):1381-1382

8. Cavalli G, De Luca G, Campochiaro C, Della-Torre E, Ripa M, Canetti D, et al. Interleukin-1 blockade with high-dose anakinra in patients with COVID-19, acute respiratory distress syndrome, and hyperinflammation: a retrospective cohort study. Lancet Rheumatol 2020;2(6):e325-e331.

9. CORIMUNO-19 Collaborative Group. Effect of anakinra versus usual care in adults in hospital with COVID-19 and mild-to-moderate pneumonia (CORIMUNO-ANA-1): a randomised controlled trial. Lancet Respir Med 2021;9(3):295-304.

10. Jia X, Liu B, Bao L, Lv Q, Li F, Li H, et al. Delayed oseltamivir plus sirolimus treatment attenuates H1N1 virus-induced severe lung injury correlated with repressed NLRP3 inflammasome activation and inflammatory cell infiltration. PLoS Pathog 2018;14(11):e1007428.

11. Zhang C, Wu Z, Li J-W, Tan K, Yang W, Zhao H, et al. Discharge may not be the end of treatment: pay attention to pulmonary fibrosis caused by severe COVID-19. J Med Virol 2020;93(3):1378-1386.

12. Lechowicz K, Drozdzal S, Machaj F, Rosik J, Szostak B, Zegan-Baranska M, et al. COVID-19: the potential treatment of pulmonary fibrosis associated with SARS-CoV-2 infection. J Clin Med 2020;9(6):1917 